\title{
Viral pneumonia: etiologies and treatment
}

\author{
Dima Dandachi, ${ }^{1}$ Maria C Rodriguez-Barradas ${ }^{1,2}$
}

${ }^{1}$ Infectious Diseases Section, Department of Medicine, Baylor College of Medicine, Houston, Texas, USA ${ }^{2}$ Infectious Diseases Section (MS 111G), Michael E. DeBakey VAMC, Houston, Texas, USA

Correspondence to Dr Maria C RodriguezBarradas, Infectious Diseases Section (MS 111G), Michael E. DeBakey Veterans Affairs Medical Center, Houston, TX 77030, USA:

maria.rodriguez-barradas2@ va.gov

Accepted 31 March 2018

Published Online First

20 April 2018

\begin{abstract}
Viral pathogens are increasingly recognized as a cause of pneumonia, in immunocompetent patients and more commonly among immunocompromised. Viral pneumonia in adults could present as community-acquired pneumonia (CAP), ranging from mild disease to severe disease requiring hospital admission and mechanical ventilation. Moreover, the role of viruses in hospital-acquired pneumonia and ventilator-associated pneumonia as causative agents or as co-pathogens and the effect of virus detection on clinical outcome are being investigated. More than 20 viruses have been linked to CAP. Clinical presentation, laboratory findings, biomarkers, and radiographic patterns are not characteristic to specific viral etiology. Currently, laboratory confirmation is most commonly done by detection of viral nucleic acid by reverse transcription-PCR of respiratory secretions.

Apart from the US Food and Drug Administrationapproved medications for treatment of influenza pneumonia, the treatment of non-influenza respiratory viruses is limited. Moreover, the evidence supporting the use of available antivirals to treat immunocompromised patients is modest at best. With the widespread use of molecular diagnostics, an aging population, and advancement in cancer therapy, physicians will face a bigger challenge in managing viral respiratory tract infections. Emphasis on infection control measures to prevent the spread of respiratory viruses especially in healthcare settings is extremely important.
\end{abstract}

\section{INTRODUCTION}

Viral pneumonia is a major cause of morbidity and mortality in the USA and around the world. The causative organisms for pneumonia vary greatly between studies depending on population studied, the diagnostic method used to detect pathogens and the seasonal distribution of the viruses. ${ }^{1-3}$

Viral pneumonia is well described in immunocompromised patients, especially among patients with hematological malignancy and transplant recipients, causing severe respiratory disease and death. More studies are showing that viral pathogens are an important cause of community-acquired pneumonia (CAP), including viruses other than influenza previously disregarded as a cause of severe disease requiring hospitalization. In a large epidemiological study conducted by the Centers for Disease Control and Prevention (CDC), despite the extensive diagnostic workup performed, no pathogen was detected in 62 per cent of the cases, viral pathogen was detected as single pathogen in 22 per cent of the cases, whereas solely bacterial pathogens were detected in 11 per cent of the cases and coinfection virusbacteria were detected in 3 per cent of the cases. Among the viral pathogens detected, human rhinovirus (HRV) was the most commonly detected followed by influenza virus. ${ }^{1}$

Moreover, viruses as an important cause for hospital-acquired pneumonia (HAP) are becoming more evident. Retrospective data from a single hospital showed viruses were isolated as frequently as bacterial pathogens in HAP cases. ${ }^{4}$ In another study looking at severe HAP, viruses were identified in 22.5 per cent of cases, most commonly respiratory syncytial virus (RSV) and parainfluenza virus. Patients with viral pneumonia had comparable mortality rates to patients with bacterial pneumonia. ${ }^{5}$

Several factors have contributed to shed light on viral respiratory pathogens as a major cause of disease, including the decline in the incidence of invasive pneumococcal disease among adults older than 50 years after the introduction of pneumococcal vaccination, the widespread use of real-time PCR (RT-PCR) to detect respiratory viruses previously unrecognized or underestimated, and an aging population more susceptible to severe viral infection. ${ }^{6}$

Among viral pathogens, influenza remains the clinically most significant viral cause of CAP in adults; other common viral pathogens include RSV, parainfluenza viruses (PIV), and adenovirus. Other viruses that have been detected in patients with CAP include rhinoviruses, coronaviruses, and human metapneumovirus (HMPV). The incidence in CAP requiring hospitalization is higher among elderly and patients with obstructive respiratory diseases. ${ }^{17}$

\section{DIAGNOSIS}

Studies have looked at clinical, laboratory, and radiographic patterns to suggest etiology of pneumonia and to guide therapy. Adult age group, rapid onset illness, elevated white blood cell, and neutrophils counts could suggest a bacterial etiology. Interstitial bilateral infiltrates as opposed to lobar alveolar infiltrates suggest viral cause. ${ }^{8}$ However, the presenting clinical features are consequently non-specific and demonstrate significant overlap between bacterial pneumonia and those with viral pneumonia, especially in case of bacterial and 
viral coinfection. In addition, elderly and immunocompromised patients with pneumonia might present with atypical manifestations making the diagnosis even more difficult. $^{910}$

Another approach to differentiate between bacterial and viral infection is to look at the host-immune responses. C-reactive protein, procalcitonin, and interleukin-6 have been used to support the diagnosis of bacterial infection. However, some studies showed that the levels of these inflammatory markers can be elevated in viral infections, questioning their diagnostic accuracy and ability to guide antimicrobial therapy. ${ }^{11}{ }^{12}$ A novel combination of viral-induced proteins that complement routinely used bacterial-induced proteins is showing promising result, can be amenable to rapid measurement, classifies mixed infections, and is unaffected by potential colonizers. ${ }^{13} 14$

Conventional ways for respiratory virus detection included isolation of the virus by viral culture and antigen detection in respiratory secretions. Introduction of highly sensitive molecular assays leads to the increase in detection rates of respiratory viruses, differentiation of virus subtypes, and discovery of new viruses that were previously difficult to identify. ${ }^{15}$ In 2008, the US Food and Drug Administration (FDA) approved the first multiplex PCR assay for the detection of multiple respiratory virus nucleic acids simultaneously. Since then, many commercial PCR panels became widely available. However, different commercially available panels can have different specificity and sensitivity for individual viruses. ${ }^{16}$

Detection of respiratory viruses in the upper respiratory tract does not imply that the virus is the underlying cause of pneumonia. When upper respiratory specimens are used such as nasopharyngeal swabs, washes, or throat swab, the presence of respiratory viruses might indicate simply an upper respiratory tract infection separate from the cause of pneumonia. The other possibility is that viruses can be detected as coinfection with bacterial organisms or facilitating lower respiratory tract bacterial infection. The interaction between viral and bacterial pathogens in pneumonia and the effect of mixed infections (bacterial and viral) versus pure bacterial infection on outcome and prognosis is still not clear. Additionally, detection of viruses might represent prolonged virus shedding especially seen in immunocompromised hosts or simply colonization of the upper airways which has been observed in healthy non-immunocompromised individuals. ${ }^{5}$

Although CT scan of the chest might be more sensitive in the diagnosis of pneumonia and suggestive of causative organism, the evidence for the validity of routine CT use in the management of pneumonia is lacking. ${ }^{17}$

\section{INFLUENZA PNEUMONIA}

Seasonal Influenza is caused by influenza A or B, and results in outbreaks and epidemics worldwide, mainly in the winter season. Influenza viruses can cause pneumonia in two different ways, primary influenza viral pneumonia and more commonly secondary bacterial pneumonia after influenza illness usually caused by Staphylococcus aureus (often methicillin-resistant), Streptococcus pneumoniae, or Streptococcus pyogenes. Influenza was the second most common pathogen detected in adult immunocompetent patients with CAP requiring hospitalization, in a study conducted between 2010 and $2012 .^{1}$

Respiratory infections caused by influenza viruses are difficult to distinguish from infections caused by other respiratory pathogens based solely on signs and symptoms. In the USA, annual epidemics occur during the fall or winter months. Rapid influenza diagnostic tests (RIDTs) detect influenza virus from respiratory secretions. These tests are highly specific and produce fast result but have low sensitivity, leading to high false negative results. Not all commercial RIDTs can differentiate between influenza $A$ and influenza $B$, and none of the available RIDT can provide information on influenza A subtypes. ${ }^{18}$ When influenza pneumonia is suspected, lower respiratory tract specimens should be collected and tested for influenza viruses by RT-PCR.

The risk of progression to lower respiratory tract infection and poor outcomes is related to host factors and viral factors. Overall, elderly patients with multiple comorbidities, solid organ transplant (SOT) and hematopoietic stem cell transplant (HSCT) patients are at higher risk of progression to pneumonia, respiratory failure, secondary bacterial infection, and death. ${ }^{19}$ In a study in patients with active or history of malignant disease and confirmed influenza virus infection, one-third of them developed pneumonia. The mortality rate approached 10 per cent. Risk factors for death were the delay in diagnosis of the influenza infection or of the bacterial or fungal superinfection. ${ }^{20}$ Similar findings were observed in HSCT recipients and patients with hematological malignancies. Pneumonia occurred in 30 per cent of patients with influenza infection. Risk factors for progression to pneumonia were an absolute lymphocyte count $<200$ cells $/ \mathrm{mL}$ and not receiving influenza-directed antiviral therapy. The absolute lymphocyte count was also an independent risk factor for death. ${ }^{21}$

Treatment should begin as soon as influenza pneumonia is suspected and before laboratory confirmation. The antiviral treatment of choice should be based on the susceptibility of the circulating virus. Currently, M2 inhibitors amantadine and rimantadine are not recommended for treatment since all circulating influenza viruses are resistant to M2 inhibitors. Three neuraminidase inhibitors are FDA approved for the treatment of influenza A and B: oral oseltamivir, inhaled zanamivir and intravenous peramivir which was approved by the FDA in 2014 to treat influenza in adult patients (table 1).

For patients with influenza pneumonia, including critically ill patients, and patients requiring mechanical ventilation, CDC guidelines recommend oseltamivir as the drug of choice. Intravenous peramivir is recommended when there is a concern about inadequate oral absorption of oseltamivir. The efficacy of peramivir in patients with severe illness and in patients with influenza B is not well established. ${ }^{18}$ Some studies demonstrated a repeated higher dose up to 5 days of intravenous peramivir compared with the low single dose recommended for uncomplicated influenza infection is safe, effective, and shortens the duration of influenza illness. ${ }^{22}$ Inhaled zanamivir is only indicated for uncomplicated acute influenza. Inhaled zanamivir lacks efficacy in pneumonia, probably due to poor bioavailability in lung periphery. ${ }^{23}$

Intravenous zanamivir is an investigational drug that could be requested for clinical use if there is a concern for 
Table 1 Medications used in the treatment for viral pneumonia

\begin{tabular}{|c|c|c|c|}
\hline Medication & Uses & & Special consideration \\
\hline Oseltamivir & $\begin{array}{l}\text { Influenza pneumonia and } \\
\text { uncomplicated influenza infection }\end{array}$ & $\begin{array}{l}\text { Oral } 75 \mathrm{mg} \text { twice daily for } 5 \text { days } \\
{ }^{*} \text { Consider longer duration for critically ill patients }\end{array}$ & $\begin{array}{l}\text { Needs dose adjustment for renal impairment, } \\
\mathrm{CrCl}<50\end{array}$ \\
\hline Peramivir & Uncomplicated influenza infection & $\begin{array}{l}\text { Intravenous } 600 \mathrm{mg} \text { single dose } \\
{ }^{*} \text { Consider repeated daily dosage up to } 5 \text { days for } \\
\text { complicated influenza infection }\end{array}$ & $\begin{array}{l}\text { Efficacy not established for serious influenza } \\
\text { infection and influenza B } \\
\text { Needs dose adjustment for renal impairment } \\
(\mathrm{CrCl})<50\end{array}$ \\
\hline Zanamivir & Uncomplicated influenza infection & $\begin{array}{l}\text { *Intravenous zanamivir investigational drug, } \\
\text { available for clinical use for oseltamivir-resistant } \\
\text { influenza strains }\end{array}$ & $\begin{array}{l}\text { Inhaled form is not recommended for influenza } \\
\text { pneumonia }\end{array}$ \\
\hline \multirow[t]{2}{*}{ Ribavirin } & \multirow[t]{2}{*}{$\begin{array}{l}{ }^{*} \text { Mostly used for RSV infection } \\
\text { in immunocompromised, used } \\
\text { anecdotally for severe PIV and } \\
\text { HMPV infection }\end{array}$} & $\begin{array}{l}{ }^{*} \text { Aerosolized } \\
2 \mathrm{~g} \text { over } 2 \text { hours every } 8 \text { hours } \pm \text { intravenous } \\
\text { immunoglobulin }\end{array}$ & $\begin{array}{l}\text { Logistically difficult to administer } \\
\text { In mechanically ventilated patients, can deposit } \\
\text { in the ventilator delivery system leading to } \\
\text { malfunction }\end{array}$ \\
\hline & & $\begin{array}{l}\text { *Systemic oral or intravenous (dosage } \\
\text { variable) } \pm \text { intravenous immunoglobulin }\end{array}$ & $\begin{array}{l}\text { Hemolytic anemia } \\
\text { Teratogenic, requires special drug handling for } \\
\text { HCW }\end{array}$ \\
\hline Cidofovir & $\begin{array}{l}\text { *Severe adenovirus infection in } \\
\text { immunocompromised } \\
\text { and immunocompetent patients }\end{array}$ & $\begin{array}{l}\text { *Intravenous } 5 \mathrm{mg} / \mathrm{kg} / \text { dose weekly, duration of } \\
\text { therapy variable, usually until symptoms resolve }\end{array}$ & $\begin{array}{l}\text { Nephrotoxicity is a major toxicity, given } \\
\text { concomitantly with intravenous hydration and } \\
\text { oral probenecid } 2 \mathrm{~g} 3 \text { hours prior to infusion then } \\
1 \mathrm{~g} \text { at } 2 \text { hours and } 8 \text { hours after completion of } \\
\text { the infusion } \\
\text { Contraindicated with pre-existing renal disease } \\
\mathrm{CrCl}<55\end{array}$ \\
\hline Acyclovir & Varicella pneumonitis & $\begin{array}{l}\text { Intravenous } 10 \mathrm{mg} / \mathrm{kg} / \text { dose every } 8 \text { hours for } \\
\text { at least } 7 \text { days }\end{array}$ & $\begin{array}{l}\text { Neurotoxicity and nephrotoxicity } \\
\text { Needs dose adjustment for } \mathrm{CrCl}<50 \\
\text { Neurotoxicity may be more common in patients } \\
\text { with renal impairment }\end{array}$ \\
\hline Ganciclovir & ${ }^{*} \mathrm{CMV}$ pneumonitis & $\begin{array}{l}\text { Intravenous } 5 \mathrm{mg} / \mathrm{kg} / \text { dose every } 12 \text { hours for } \\
\text { at least } 2 \text { weeks }\end{array}$ & $\begin{array}{l}\text { Hematological toxicity (anemia, } \\
\text { thrombocytopenia, leucopenia), nephrotoxicity } \\
\text { and gastrointestinal symptom } \\
\text { Needs dose adjustment for } \mathrm{CrCl}<70\end{array}$ \\
\hline
\end{tabular}

*Off-label use.

$\mathrm{CMV}$, cytomegalovirus; $\mathrm{CrCl}$, creatinine clearance; HCW, healthcare workers; HMPV, human metapneumovirus; PIV, parainfluenza viruses; RSV, respiratory syncytial virus.

oseltamivir-resistant influenza strain. Depending on the mutation conferring the resistance, the virus might develop resistance to oseltamivir but remain susceptible to zanamivir. ${ }^{24}$ Other drugs showing potent antiviral activity are being tested in vitro and considered for potential therapy for multidrug-resistant influenza viruses, for example, the first class of organosilanes that have potent antiviral activity against influenza $\mathrm{A}$ viruses that are resistant to amantadine and oseltamivir. ${ }^{25}$ Another medication, dapivirine, an FDA-approved HIV non-nucleoside reverse transcriptase inhibitor, has broad-spectrum antiviral activity against multiple strains of influenza A and B viruses. ${ }^{26}$

When there is high clinical suspicion for influenza pneumonia, the treatment should be started regardless of time of presentation and continue even if initial influenza test result is negative, unless an alternative diagnosis exists. Patients who are severely ill with influenza should be evaluated for a secondary bacterial pneumonia.

Influenza vaccine remains the most effective way to prevent seasonal influenza and influenza-related complications. Since 2010, the CDC's Advisory Committee on Immunization Practices has recommended annual influenza vaccination for all persons aged $\geq 6$ months who do not have contraindications. Each year, generally around February, recommendations for the composition of influenza vaccines are made based on surveillance data and a report is released focusing on changes in the viral antigen composition of seasonal influenza vaccines and providing guidance for vaccine providers. The optimal timing of vaccination should be before the onset of influenza activity in the area. However, if given early in the season, there is a potential risk for suboptimal immunity by the end of the influenza season, especially in elderly population. The effectiveness of influenza vaccines among older adults is an area of active research and no formal recommendation has been made regarding specific dosage or formulation. ${ }^{27}$

\section{PANDEMIC INFLUENZA}

The 1918 influenza A virus pandemic was the first well-documented influenza pandemic of the 20th century. In 2005, researchers were able to reconstruct the virus after sequencing of the full RNA genome. This work provided important information on the evolution, antigenic properties, pathogenic determinants and virulence markers of the virus which facilitated the rapid assessment of the potential for pandemic spread of subsequent emerging virus.

\section{AVIAN AND SWINE INFLUENZA}

Zoonotic influenza viruses are distinct from human seasonal influenza viruses and do not easily transmit between humans. In addition, a number of viral genetic changes are 
required for adaptation to humans. Distinguishing avian or swine influenza from seasonal influenza is difficult; however, patients usually have a more aggressive clinical course. Upper respiratory tract symptoms are less common.

In 2003, with the avian influenza A (H5N1) epidemic, almost all patients developed pneumonia early during their illness. Multifocal consolidation was the most frequent finding at presentation. Most patients died of respiratory failure with case fatality rate of 59 per cent. ${ }^{28}$ In 2009, a novel virus caused the pandemic swine-origin influenza A (H1N1). There is much variability in estimates of patients who developed viral pneumonia during this epidemic, secondary bacterial infection was reported in 20-24 per cent of patients. Poor outcomes were associated with younger age, pregnancy, obesity, and patients with underlying comorbidities. Mortality rate for hospitalized patients ranged from 4.1 to 46 per cent. ${ }^{29}{ }^{30}$ Treatment is similar to that of seasonal influenza virus. Current vaccines do not provide cross-protection against strains of the $\mathrm{H} 5, \mathrm{H} 7$, and H9 influenza viruses. ${ }^{31}$

The similarity in the virulence markers between the 1918 virus and the $\mathrm{H} 5 \mathrm{~N} 1$ and $\mathrm{H} 7 \mathrm{~N} 9$ avian influenza viruses has highlighted the pandemic potential for these viruses ${ }^{32}$ and the need for continuous vigilance for any human cases.

\section{PARAMYXOVIRUSES}

RSV, PIV and HMPV are paramyxoviruses and important respiratory pathogens. These infections are usually acquired in early childhood. Almost all adults are seropositive, but immunity is incomplete, and reinfection can occur in adulthood.

\section{RSV PNEUMONIA}

RSV causes acute respiratory tract illness in persons of all ages. Traditionally a viral pathogen of children, RSV can cause CAP in adults that could be particularly severe in older adults and immunocompromised individuals with a mortality rate similar to influenza-attributable mortality. ${ }^{33}$ Clinical features are not distinct from other causes of viral pneumonia. Patients usually present with symptoms of upper respiratory tract infection followed by pneumonia. Wheezing is a common feature in RSV pneumonia. ${ }^{34}$

Among HSCT recipients and patients with hematological malignancy, RSV is a significant cause of pneumonia. Risk of progression to pneumonia ranged from 18 to 55 per cent. ${ }^{15}$ Pneumonia and mortality rates are higher when RSV is contracted in the first few months after HSCT; other risk factors include presence of graft versus host disease, increasing age, and myeloablative conditioning. ${ }^{15} 2135$ RSV infection is associated with decrease in pulmonary function tests and development of bronchiolitis obliterans syndrome after lung transplantation. ${ }^{36}$

The treatment of RSV pneumonia is supportive. Ribavirin (table 1) is approved by the FDA for the treatment of RSV in children. However, systemic or aerosolized ribavirin has been used off-label in the treatment of RSV infection with or without intravenous immunoglobulins in immunocompromised subjects, particularly among lung transplant and HSCT recipients. There are no comparative data between aerosolized versus oral or intravenous ribavirin. Most of the research available support the use of ribavirin in immunocompromised patients with RSV pneumonia. Studies have shown that the use of aerosolized ribavirin prevented progression to lower respiratory tract infection when given early in the disease and decrease mortality in patients with RSV pneumonia. ${ }^{37} 38$ When considering using aerosolized ribavirin, cost, potential bronchospasm, and teratogenicity risk for healthcare workers (HCWs) should be taken into account. ${ }^{36}$ In contrast to earlier studies showing high rates of hemolytic anemia with the use of systemic ribavirin, more recent studies showed that oral ribavirin was well tolerated in patients with various degrees of immunosuppression. ${ }^{39} 40$ Treatment with oral ribavirin prevented the development of bronchiolitis obliterans, decreased mortality in lung transplant patients with RSV pneumonia, and reduced the cost compared with aerosolized ribavirin. ${ }^{41}{ }^{42}$ Ribavirin intravenous was also investigated with mixed results, some studies did not show a mortality benefit in patients with RSV pneumonia, ${ }^{43}$ while other studies showed a more favorable outcome. ${ }^{44}$

A systematic review looking at the management of RSV infection in adult HSCT recipients showed a trend towards a better outcome regarding RSV-related or attributable mortality in patients treated with aerosolized ribavirin with intravenous immunoglobulin or RSV-specific intravenous immunoglobulin than in those treated with ribavirin alone. ${ }^{45}$ Similarly, a study among patients with lung transplant suggested an aggressive multidrug regimen approach including inhaled ribavirin, corticosteroids, and intravenous immunoglobulin (with or without palivizumab) to preserve lung function in patients with RSV infection. ${ }^{4647}$

Palivizumab, a humanized RSV monoclonal antibody, was approved by the FDA in 1998 for the prevention of serious lower respiratory tract infections caused by RSV in children at increased risk of severe disease. ${ }^{48}$ The use of palivizumab as prophylaxis and treatment in immunocompromised patients has not been well studied and thus is not recommended. Small studies showed that palivizumab in addition to strict infection control measures was effective in controlling a nosocomial outbreak of RSV in a stem cell transplantation unit. ${ }^{49}$ A phase I study showed that palivizumab as single intravenous infusion in combination with aerosolized ribavirin to treat RSV infection among HSCT recipients was safe and well tolerated. ${ }^{50}$

Motavizumab, another humanized IgG1 monoclonal antibody, with a higher affinity for RSV than palivizumab, was effective in reducing RSV-related hospital admissions among healthy term native American infants before the FDA declined to approve licensure for side effects concerns. ${ }^{51}$

Many medications are under development for the prevention and treatment of RSV infection. A new drug advanced to phase II clinical trial, presatovir (GS-5806), is a potent and selective RSV fusion inhibitor that will block the viruscell fusion process, currently being evaluated in elderly and with an acute RSV lower respiratory tract infection. ${ }^{52}$

\section{PIV PNEUMONIA}

There are three PIV serotypes, 1, 2 and 3. PIV infection is the leading cause of croup in children. PIV circulation has seasonal variation, depending on the region. In the USA, PIV serotype 3 is the most prevalent serotype and usually causes outbreaks in the months of April to June. Whereas 
PIV-1 and PIV-2 are more commonly encountered during the fall. PIV-3 is the most prevalent serotype in adults hospitalized with pneumonia. ${ }^{53}$

In healthy adults, with no underlying immunodeficiency, PIV infection could be asymptomatic or could cause mild upper respiratory infection. PIV infection is associated with asthma and chronic obstructive pulmonary disease exacerbation. In a study comparing the clinical characteristics of PIV pneumonia to non-PIV pneumonia, wheezing was reported more frequently. ${ }^{54}$ Several risk factors are associated with progression to pneumonia and severe disease including older age, steroid use, and immunocompromised status.

Among patients with hematological malignancy and HSCT and PIV infection, the average incidence of PIV pneumonia was 37 per cent. Predictors for progression to lower respiratory tract infection were early-onset infection post-transplant, steroid use, and coinfection with other pathogens. ${ }^{55}$ In a systematic review, the average mortality rate for patients with PIV pneumonia was 27 per cent. Other mortality risk factors were steroid use, presence of co-pathogens, and relapsed or refractory underlying malignancy. ${ }^{56-58}$

There is no proven effective treatment available for PIV pneumonia. Ribavirin has antiviral activity against PIV and has been used anecdotally in different forms for the treatment of PIV-associated pneumonia in immunocompromised patients. ${ }^{59}{ }^{60}$ However, the clinical benefit of treatment is uncertain. ${ }^{215661}$

DAS181 is a new sialidase fusion protein that targets host sialic acid receptor, preventing the virus from cell attachment and entry; it has been tested in small clinical trials for the treatment of PIV showing some clinical improvement and no major adverse events. ${ }^{62}$ Suramin acts as a non-competitive hemagglutinin-neuraminidase inhibitor, inhibiting viral replication in mammalian epithelial cells. Suramin could be a potential treatment for PIV infection. ${ }^{35}{ }^{63} \mathrm{~A}$ lot of interest is being focused on developing short interfering RNAs (siRNAs) against viral genes. siRNAs demonstrated antiviral activity in cell culture and prevented RSV and PIV infection when instilled intranasally in a mouse model. ${ }^{64}$

\section{HMPV PNEUMONIA}

The risk of pneumonia and severe disease due to HMPV infection is higher in elderly patients with chronic cardiorespiratory disease and immunocompromised. ${ }^{19}{ }^{65}$ Rates of progression to pneumonia and death are different between studies, but are becoming more recognized that HMPV can cause pneumonia and can have high morbidity and mortality. ${ }^{15} 6667$ In patients with lung transplant, some studies suggest that HMPV infection (without specifying upper vs lower respiratory tract infection) could be associated with acute and chronic allograft rejection. ${ }^{68} 69$

The treatment for HMPV pneumonia is largely supportive. Oral, aerosolized, or intravenous ribavirin and intravenous immunoglobulin have been used for severely ill immunocompromised patients with mixed results. ${ }^{6670}$ Recently, a cross-reactive $\mathrm{mAb}$ with activity against both RSV and HMPV fusion (F) protein has been discovered and could possibly have an implication on the development of clinical antibodies and vaccines that elicit neutralizing antibodies against these two viruses. ${ }^{71}$

Vaccines based on live-attenuated chimeric and recombinant vaccines against RSV and HMPV and human PIV 1-3 are under development. ${ }^{72}$ A recent phase IIb study, assessing a RSV post-fusion F-based vaccine efficacy in adults $\geq 60$ years of age, failed to prevent RSV-associated acute respiratory illness despite developing a positive antibody seroresponse. ${ }^{73}$

\section{ADENOVIRUS PNEUMONIA}

Human adenoviruses (HAdVs) are double-stranded DNA viruses. HAdVs cause different clinical syndromes depending on the adenovirus serotype, viral tropism, portal of entry, and host factors. Respiratory infections could be associated with gastrointestinal symptoms. Respiratory illnesses in adult immunocompetent patients are often mild and self-limited. However, severe pneumonia, respiratory failure, and high fatality have been reported in sporadic cases, in outbreaks among military recruits and institutional settings, and even community-based outbreaks in the USA and around the world. ${ }^{7-77}$ Severe adenovirus infection has also been described in patients with HSCT and SOT ranging from asymptomatic shedding to severe fatal pneumonia as part of disseminated disease. In cases of adenovirus pneumonia, mortality rate was high. Even among immunocompetent patients, mortality was 26.7 per cent ${ }^{77}$ and can reach 50 per cent in some studies. ${ }^{15}$

Currently, there is no FDA-approved treatment for the adenovirus infection. Cidofovir (table 1) has good in vitro activity against all adenovirus serotypes. Few case series showed clinical improvement with the use of cidofovir with or without intravenous immunoglobulin among patients with severe adenovirus pneumonia but its use is limited by toxicities and low-quality evidence. Hydration and probenecid should be given along with cidofovir to prevent renal toxicity. ${ }^{78}$

Brincidofovir (CMX001), an orally bioavailable lipid conjugate of cidofovir, could be a promising medication for the treatment of adenovirus in severe cases. ${ }^{79}$

Live oral vaccine against adenoviruses types 4 and 7 has been available since 1971 and has shown to be safe and highly effective. It was discontinued and reintroduced after the adenovirus military outbreaks in 2001. Its use is currently restricted for military use. ${ }^{80}$

\section{HUMAN RHINOVIRUSES}

HRV are among the most common pathogens causing common cold in adults, mild self-limited upper respiratory tract infection. With the advancement in molecular diagnostics, the clinical significance of detecting HRV in the lower respiratory tract and their ability to cause pneumonia is debated. However, more evidence supports that HRV could have a serious pathogenic role in lower respiratory tract infections, although uncommon, in the elderly and immunocompromised patients. ${ }^{81}{ }^{82}$ Lower respiratory tract infection with HRV had similar outcome compared with infection with RSV, PIV or influenza virus. ${ }^{83}$ Among patients with lung transplant, some studies showed that persistent infection of HRV was associated with acute and chronic graft rejection and increased mortality, other studies were not able to prove this association. ${ }^{84} 85$ 
Despite extensive efforts, there is still no proven effective therapy to treat HRV infection. In a small group of patients with primary hypogammaglobulinemia, the combination of interferon and ribavirin was associated with rapid decrease of HRV. ${ }^{86}$ Novel antiviral therapy targeting the $3 \mathrm{C}$ protease protein has been developed with modest clinical effect. Another class of antivirals that were tested were the capsid binding drugs preventing the attachment between the virus and host cell receptors; of those, pleconaril was rejected by the FDA for side effects and vapendavir failed to meet its primary endpoints in a clinical trial. ${ }^{87}$

\section{HUMAN CORONAVIRUSES (HCOV)}

HCoV strains (HCoV-229E, HCoV-OC43, HCoV-NL63, and CoV-HKU1) are primarily respiratory viruses that replicate in the epithelial cells of the nasopharynx and cause common cold symptoms with similar presentation to the infection by rhinovirus. Due to enhanced molecular methods, $\mathrm{HCoV}$ have been identified as possible etiological agents in $\mathrm{CAP}^{88}$ However, $\mathrm{HCoV}$ gain more importance as a cause of severe lower respiratory infection and death with the emergence of the novel HCoVs, severe acute respiratory syndrome coronavirus and Middle East respiratory syndrome coronavirus (MERS-CoV).

\section{SEVERE ACUTE RESPIRATORY SYNDROME (SARS)}

In 2002, an outbreak of atypical pneumonia was reported from China with high rate of nosocomial transmission. This was followed by the identification of a coronavirus as the causative agent for SARS, subsequently named SARS-CoV. From 2002 to 2003, the SARS epidemic spread globally. There were a total of 8096 reported cases from 27 countries, with the highest number of cases recorded in China. ${ }^{89}$

Clinical manifestations were predominantly respiratory ranging from mild to severe disease, respiratory failure, and death; the case-fatality rate was estimated to be 10 per cent. ${ }^{90}$

\section{MIDDLE EAST RESPIRATORY SYNDROME}

MERS is a viral respiratory disease caused by the MERS-CoV. The first cases were described from Saudi Arabia in 2012. Since then, 2066 laboratory-confirmed cases were reported to WHO, 82 per cent of whom were reported by Saudi Arabia. Thus, MERS should be considered in travelers or close contacts with travelers to the Middle East, particularly to the Arabian Peninsula within 2 weeks before symptom onset.

Although not clearly understood, there is evidence to suggest transmission from the Arabian camel to humans; in spite of that, most patients do not recall any contact. MERS-CoV is considered a zoonotic virus; human-tohuman transmission has been documented but limited to healthcare facilities and close contacts to patients with MERS-CoV infection. The clinical spectrum ranges from asymptomatic to mild respiratory symptoms to severe acute respiratory disease. Pneumonia is a common presentation with fever, cough, and shortness of breath progressing to respiratory failure. Mortality rate has been reported to be 35 per cent, with 720 documented deaths, which is threefold higher than for SARS. ${ }^{91}$
Treatment of both SARS and MERS remains supportive. A range of treatment options has been suggested but remains investigational. The use of convalescent plasma therapy has been used for SARS and proposed for MERS, with some favorable outcomes when given early in the disease. ${ }^{92}$ The treatment with systemic steroids did not improve outcome; in contrast, it was associated with prolonged viremia and increased mortality. ${ }^{93}$ Interferon and ribavirin with or without lopinavir/ritonavir have been used in animal studies and small clinical studies with inconclusive results. ${ }^{95}{ }^{96}$ Drug discoveries classified into virus-based and host-based treatment options are under development. ${ }^{94}$ Different vaccination strategies against SARS-CoV and MERS-CoV are developed and being tested in animal models. ${ }^{90}$

\section{PNEUMONIA BY HUMAN HERPESVIRUSES Varicella pneumonia}

The incidence of varicella-zoster virus (VZV), or HHV-3 disease, has decreased after the introduction of varicella vaccine. Infections occur after inhalation of infected droplets or by contact with skin lesions. VZV infection can have several different presentations depending on the age and immune status of the patient. Primary varicella infection in older patients, immunocompromised, people living with HIV and pregnant women is usually severe and can have an atypical presentation. Patients can have widespread disease in the absence of skin lesions or can develop severe interstitial pneumonia that progress to acute respiratory distress syndrome. ${ }^{97}$

Lung involvement occurs within the first sevendays of the disease. Chest radiographs show diffuse bilateral interstitial or micronodular infiltrates. The mortality is high in these patients and can reach 18 per cent. In patients with varicella pneumonitis, antiviral therapy with highdose acyclovir should not be delayed until the diagnosis is confirmed and should continue for a minimum of 7 days. The use of steroids as adjunctive therapy is controversial. ${ }^{98}$

The vaccine is available either as a single live attenuated vaccine or as a combination with mumps and rubella vaccine. For persons who are exposed to varicella and had no evidence of immunity, postexposure vaccination is recommended. ${ }^{99}$

\section{CYTOMEGALOVIRUS (CMV) PNEUMONIA}

Most CMV infections are asymptomatic and acquired in early age. After primary infection, the virus remains latent in body cells and present later as reactivation. Solid organ transplant and HSCT recipients are at highest risk for CMV pneumonia. The chest radiographic findings of CMV pneumonitis are consistent with interstitial pneumonia, usually bilateral and symmetrical. The diagnosis is suspected when there is a positive CMV PCR assay of bronchoalveolar lavage (BAL) fluid or if there are cytopathic changes induced by CMV seen on cytological examination of BAL fluid cells. A definitive diagnosis requires lung biopsy showing changes consistent with CMV infection. Quantification of CMV viral load on BAL fluid can be used to assist in the diagnosis of CMV pneumonia. ${ }^{100}$

The drug of choice for CMV pneumonitis is intravenous ganciclovir. The efficacy of oral valganciclovir has not been established. There are limited data on the added 
benefit of CMV immunoglobulin. Foscarnet and cidofovir are reserved for the treatment of resistant infections. CMV vaccine remains under study with glycoprotein $B$ conjugate the leading candidate under consideration. ${ }^{101}$

\section{HERPES SIMPLEX VIRUS (HSV)}

The detection of HSV in lower respiratory secretions is increasingly reported in critically ill patients, immunocompetent and immunocompromised. The recovery of HSV virus in lower respiratory tract could be the result of a contamination from the upper respiratory tract or local viral reactivation. Whether HSV represents a marker of severe disease or true pathogen that is associated with respiratory disease, lung injury and mortality is not clear. ${ }^{102}$ Some studies showed an association between HSV viral load in BAL and poor outcome. ${ }^{103}$ The need for antiviral treatment in patients with HSV remains to be investigated in randomized controlled trials. ${ }^{104}$

\section{TRANSMISSION AND INFECTION CONTROL MEASURES IN HEALTHCARE SETTINGS}

Nosocomial acquisition of viral RTI is not uncommon and possibly underestimated; it can have grave impacts on patient outcomes and health-related costs. ${ }^{105}$ Many outbreaks have been reported with widespread infection in hospital settings for nearly all respiratory viruses. Strict implementation of infection control measures is very important to prevent spread of infection particularly at times of outbreaks and among immunocompromised patients. ${ }^{106}$ We will summarize the infection control practices advised by the CDC and the Health Care Infection Control Practices Advisory Committee (HICPAC). ${ }^{107} 108$ These practices vary widely among different institutions. ${ }^{35}$

For HCWs with signs of respiratory illness, run rapid diagnostics and restrict from caring for high-risk patients. Educate staff and symptomatic patients about respiratory hygiene and cough etiquette. HICPAC recommends empiric contact plus droplet isolation precautions for respiratory illness on presentation before diagnosis and for patients presenting with possible pneumonia and a recent travel history to countries with active outbreaks of novel respiratory infections airborne, contact precautions plus eye protection.

Standard precautions should be applied to all patients in addition to transmission-based precautions. For HRV and seasonal influenza, droplet is the most important route of transmission and thus droplet precautions should be implemented. In addition, airborne precautions should be applied when performing aerosol-generating procedures in case of influenza pneumonia.

Another infection control measure is to place patients with viral respiratory infections in single rooms, when available, or to cohort them.

Although RSV may be transmitted by the droplet route, direct contact with infected respiratory secretions is the most important determinant of transmission, similarly for PIV and HMPV. Contact precaution in addition to standard precaution should be applied in case of RSV, HMPV or PIV infection. In case of adenovirus infection, contact, droplet, and standard precautions should be applied. Standard, contact, and airborne isolation should be applied when dealing with suspected or confirmed cases of novel Influenza A, SARS, or MERS infection. Patients with active varicella should be promptly separated from seronegative patients and should be placed under airborne and contact isolation.

Patients who are immunocompromised have prolonged virus shedding and could require a longer duration of isolation. ${ }^{109}$ During periods of influenza or RSV circulation in the community, consider restricting or screening visitors for respiratory illness.

\section{CONCLUSION}

Viruses represent a common cause of CAP as well as HAP. Clinical manifestations and severity of illness vary depending on age, immune status, and comorbidities. Diagnosis is usually made by detection of virus by RT-PCR in upper or lower respiratory secretions. However, tests results should be interpreted with caution and take into account the clinical presentation and the prevalence of the virus in the population tested. Treatment is mainly supportive. The only FDA-approved medications for the treatment of viral pneumonia in adults are the neuraminidase inhibitors oseltamivir and peramivir. Infection control practices in the hospital are very important especially at times of outbreaks and epidemics.

Contributors All authors have reviewed and approved the content and have contributed significantly to the work.

Funding The authors have not declared a specific grant for this research from any funding agency in the public, commercial or not-for-profit sectors.

Competing interests None declared.

Patient consent Not required.

Provenance and peer review Commissioned; externally peer reviewed.

(c) American Federation for Medical Research (unless otherwise stated in the text of the article) 2018. All rights reserved. No commercial use is permitted unless otherwise expressly granted.

\section{REFERENCES}

1 Jain S, Self WH, Wunderink RG, et al. Community-Acquired Pneumonia requiring hospitalization among U.S. adults. $N$ Engl J Med Overseas Ed 2015;373:415-27.

2 GBoDS C. Global, regional, and national incidence, prevalence, and years lived with disability for 301 acute and chronic diseases and injuries in 188 countries, 1990-2013: a systematic analysis for the Global Burden of Disease Study 2013. Lancet 2015:386:743-800.

3 World Health Organisation. The top 10 causes of death. 2017. http://www. who.int/mediacentre/factsheets/fs310/en/ (accessed 30 Aug 2017).

4 Shorr AF, Zilberberg MD, Micek ST, et al. Viruses are prevalent in nonventilated hospital-acquired pneumonia. Respir Med 2017;122:76-80.

5 Hong HL, Hong SB, Ko GB, et al. Viral infection is not uncommon in adult patients with severe hospital-acquired pneumonia. PLoS One 2014;9:e95865.

6 Lexau CA, et al. Changing epidemiology of invasive pneumococcal disease among older adults in the era of pediatric pneumococcal conjugate vaccine. JAMA 2005;294:2043-51.

7 Alimi Y, Lim WS, Lansbury L, et al. Systematic review of respiratory viral pathogens identified in adults with community-acquired pneumonia in Europe. Journal of Clinical Virology 2017;95:26-35.

8 Ruuskanen 0, Lahti E, Jennings LC, et al. Viral pneumonia. The Lancet 2011;377:1264-75.

9 Çağlayan Serin D, Pullukçu H, Çiçek C, et al. Bacterial and viral etiology in hospitalized community acquired pneumonia with molecular methods and clinical evaluation. The Journal of Infection in Developing Countries 2014;8:510-8.

10 Hoshina T, Nanishi E, Kanno S, et al. The utility of biomarkers in differentiating bacterial from non-bacterial lower respiratory tract infection in hospitalized children: difference of the diagnostic performance between 
acute pneumonia and bronchitis. Journal of Infection and Chemotherapy 2014;20:616-20.

11 Dominguez O, Rojo P, de las Heras S, et al. Clinical presentation and characteristics of pharyngeal adenovirus infections. Pediatr Infect Dis $J$ 2005;24:733-4.

12 Nohynek H, Valkeila E, Leinonen M, et al. Erythrocyte sedimentation rate, white blood cell count and serum C-reactive protein in assessing etiologic diagnosis of acute lower respiratory infections in children. Pediatr Infect Dis $J$ 1995:14:484-9.

13 Oved K, Cohen A, Boico O, et al. A novel host-proteome signature for distinguishing between acute bacterial and viral infections. PLoS One 2015;10:e0120012.

14 van Houten CB, de Groot JAH, Klein A, et al. A host-protein based assay to differentiate between bacterial and viral infections in preschool children (OPPORTUNITY): a double-blind, multicentre, validation study. Lancet Infect Dis 2017;17:431-40.

15 Renaud C, Campbell AP. Changing epidemiology of respiratory viral infections in hematopoietic cell transplant recipients and solid organ transplant recipients. Curr Opin Infect Dis 2011;24:333-43.

16 Balada-Llasat J-M, LaRue H, Kelly C, et al. Evaluation of commercial ResPlex Il v2.0, MultiCode $®-P L x$, and XTAG® respiratory viral panels for the diagnosis of respiratory viral infections in adults. Journal of Clinical Virology 2011;50:42-5.

17 Mandell LA, Wunderink RG, Anzueto A, et al. Infectious diseases society of america/american thoracic society consensus guidelines on the management of community-acquired pneumonia in adults. Clinical Infectious Diseases 2007:44:S27-72.

18 CDC. Seasonal Influenza (Flu). 2016. https://www.cdc.gov/flu/professionals/ (accessed 27 Aug 2017).

19 Ramsey CD, Kumar A. Influenza and endemic viral pneumonia. Crit Care Clin 2013;29:1069-86.

20 Hermann B, Lehners $N$, Brodhun $M$, et al. Influenza virus infections in patients with malignancies characteristics and outcome of the season 2014/15. A survey conducted by the Infectious Diseases Working Party (AGIHO) of the German Society of Haematology and Medical Oncology (DGHO). European Journal of Clinical Microbiology \& Infectious Diseases 2017:36:565-73.

21 Chemaly RF, Ghosh S, Bodey GP, et al. Respiratory viral infections in adults with hematologic malignancies and human stem cell transplantation recipients: a retrospective study at a major cancer center. Medicine 2006:85:278-87.

22 Kohno S, Kida H, Mizuguchi M, et al. Intravenous peramivir for treatment of influenza $\mathrm{a}$ and $\mathrm{b}$ virus infection in high-risk patients. Antimicrob Agents Chemother 2011;55:2803-12.

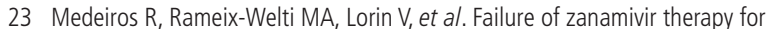
pneumonia in a bone-marrow transplant recipient infected by a zanamivirsensitive influenza A (H1N1) virus. Antivir Ther 2007:12:571-6.

24 Kawai $\mathrm{N}$, Ikematsu $\mathrm{H}$, Iwaki $\mathrm{N}$, et al. Comparison of the effectiveness of Zanamivir and Oseltamivir against Influenza A/H1N1, A/H3N2, and B. Clinical Infectious Diseases 2009;48:996-7.

$25 \mathrm{Hu}$ Y, Wang Y, Li F, et al. Design and expeditious synthesis of organosilanes as potent antivirals targeting multidrug-resistant influenza A viruses. Eur J Med Chem 2017; 135:70-6.

26 Hu Y, Zhang J, Musharrafieh RG, et al. Discovery of dapivirine, a nonnucleoside HIV-1 reverse transcriptase inhibitor, as a broad-spectrum antiviral against both influenza A and B viruses. Antiviral Res 2017;145:103-13.

27 Grohskopf LA, Sokolow LZ, Broder KR, et al. Prevention and control of seasonal influenza with vaccines: recommendations of the advisory committee on immunization practices — United States, 2017-18 Influenza Season. MMWR. Recommendations and Reports 2017;66:1-20.

28 Beigel JH, Farrar J, Han AM, et al. Avian influenza A (H5N1) infection in humans. N Eng/ J Med 2005:353:1374-85.

29 Bautista E, Chotpitayasunondh T, Gao Z, et al. Clinical aspects of pandemic 2009 influenza A (H1N1) virus infection. N Engl J Med 2010;362:1708-19.

30 Poeppl W, Hell M, Herkner H, et al. Clinical aspects of 2009 pandemic influenza A (H1N1) virus infection in Austria. Infection 2011;39:341-52.

31 Tang J, Wang D. Research progress in human infection with avian influenza H7N9 virus. Sci China Life Sci 2017.

32 Medina RA. 1918 influenza virus: 100 years on, are we prepared against the next influenza pandemic? Nat Rev Microbiol 2018;16:61-2.

33 Branche AR, Falsey AR. Respiratory syncytial virus infection in older adults: an under-recognized problem. Drugs Aging 2015;32:261-9.

34 Cesario TC. Viruses associated with pneumonia in adults. Clinical Infectious Diseases 2012;55:107-13.
35 Abbas S, Raybould JE, Sastry S, et al. Respiratory viruses in transplant recipients: more than just a cold. Clinical syndromes and infection prevention principles. International Journal of Infectious Diseases 2017;62:86-93.

36 Kim Y-J, Boeckh M, Englund J. Community respiratory virus infections in immunocompromised patients: hematopoietic stem cell and solid organ transplant recipients, and individuals with human immunodeficiency virus infection. Semin Respir Crit Care Med 2007;28:222-42.

37 Boeckh M, Englund J, Li Y, et al. Randomized controlled multicenter trial of aerosolized ribavirin for respiratory syncytial virus upper respiratory tract infection in hematopoietic cell transplant recipients. Clinical Infectious Diseases 2007;44:245-9.

38 Waghmare A, Campbell AP, Xie H, et al. Respiratory syncytial virus lower respiratory disease in hematopoietic cell transplant recipients: viral rna detection in blood, antiviral treatment, and clinical outcomes. Clinical Infectious Diseases 2013;57:1731-41.

39 Marcelin JR, Wilson JW, Razonable RR, et al. Oral ribavirin therapy for respiratory syncytial virus infections in moderately to severely immunocompromised patients. Transplant Infectious Disease 2014; 16:242-50.

40 Gorcea CM, Tholouli E, Turner A, et al. Effective use of oral ribavirin for respiratory syncytial viral infections in allogeneic haematopoietic stem cell transplant recipients. J Hosp Infect 2017;95:214-7.

41 Burrows FS, Carlos LM, Benzimra M, et al. Oral ribavirin for respiratory syncytial virus infection after lung transplantation: Efficacy and cost-efficiency. The Journal of Heart and Lung Transplantation 2015;34:958-62.

42 Pelaez A, Lyon GM, Force SD, et al. Efficacy of oral ribavirin in lung transplant patients with respiratory syncytial virus lower respiratory tract infection. The Journal of Heart and Lung Transplantation 2009;28:67-71.

43 Lewinsohn DM, Bowden RA, Mattson D, et al. Phase I study of intravenous ribavirin treatment of respiratory syncytial virus pneumonia after marrow transplantation. Antimicrob Agents Chemother 1996;40:2555-7.

44 Glanville AR, Scott AIR, Morton JM, et al. Intravenous Ribavirin is a safe and cost-effective treatment for respiratory syncytial virus infection after lung transplantation. The Journal of Heart and Lung Transplantation 2005;24:2114-9.

45 Shah JN, Chemaly RF. Management of RSV infections in adult recipients of hematopoietic stem cell transplantation. Blood 2011;117:2755-63.

46 Liu V, Dhillon GS, Weill D. A multi-drug regimen for respiratory syncytial virus and parainfluenza virus infections in adult lung and heart-lung transplant recipients. Transplant Infectious Disease 2010;12:38-44.

47 Hynicka LM, Ensor CR. Prophylaxis and treatment of respiratory syncytial virus in adult immunocompromised patients. Ann Pharmacother 2012:46:558-66.

48 AAoPCol D, AAoPBG C. Updated guidance for palivizumab prophylaxis among infants and young children at increased risk of hospitalization for respiratory syncytial virus infection. Pediatrics 2014;134:415-20.

49 Kassis C, Champlin RE, Hachem RY, et al. Detection and control of a nosocomial respiratory syncytial virus outbreak in a stem cell transplantation unit: the role of palivizumab. Biology of Blood and Marrow Transplantation 2010;16:1265-71.

50 Boeckh M, Berrey MM, Bowden RA, et al. Phase 1 Evaluation of the respiratory syncytial virus-specific monoclonal antibody palivizumab in recipients of hematopoietic stem cell transplants. J Infect Dis 2001;184:350-4.

51 O'Brien KL, Chandran A, Weatherholtz R, et al. Efficacy of motavizumab for the prevention of respiratory syncytial virus disease in healthy Native American infants: a phase 3 randomised double-blind placebo-controlled trial. Lancet Infect Dis 2015;15:1398-408.

52 Perron M, Stray K, Kinkade A, et al. GS-5806 Inhibits a broad range of respiratory syncytial virus clinical isolates by blocking the virus-cell fusion process. Antimicrob Agents Chemother 2016:60:1264-73.

53 Russell E, Ison MG. Parainfluenza virus in the hospitalized adult. Clin Infect Dis 2017.

54 Marx A, Gary, Jr. HE, Marston BJ, et al. Parainfluenza virus infection among adults hospitalized for lower respiratory tract infection. Clinical Infectious Diseases 1999;29:134-40.

55 Shah DP, Shah PK, Azzi JM, et al. Parainfluenza virus infections in hematopoietic cell transplant recipients and hematologic malignancy patients: A systematic review. Cancer Lett 2016:370:358-64.

56 Nichols WG, et al. Parainfluenza virus infections after hematopoietic stem cell transplantation: risk factors, response to antiviral therapy, and effect on transplant outcome. Blood 2001;98:573-8.

57 Lewis VA, Champlin R, Englund J, et al. Respiratory disease due to parainfluenza virus in adult bone marrow transplant recipients. Clinical Infectious Diseases 1996:23:1033-7. 
58 Chemaly RF, Hanmod SS, Rathod DB, et al. The characteristics and outcomes of parainfluenza virus infections in 200 patients with leukemia or recipients of hematopoietic stem cell transplantation. Blood 2012;119:2738-45. Quiz 2969.

59 Wright JJ, O’Driscoll G. Treatment of parainfluenza virus 3 pneumonia in a cardiac transplant recipient with intravenous ribavirin and methylprednisolone. The Journal of Heart and Lung Transplantation 2005:24:343-6.

60 Shima T, Yoshimoto G, Nonami A, et al. Successful treatment of parainfluenza virus 3 pneumonia with oral ribavirin and methylprednisolone in a bone marrow transplant recipient. Int J Hematol 2008;88:336-40.

61 Maziarz RT, Sridharan P, Slater S, et al. Control of an outbreak of human parainfluenza virus 3 in hematopoietic stem cell transplant recipients. Biology of Blood and Marrow Transplantation 2010;16:192-8.

62 Salvatore M, Satlin MJ, Jacobs SE, et al. DAS181 for Treatment of parainfluenza virus infections in hematopoietic stem cell transplant recipients at a single center. Biology of Blood and Marrow Transplantation 2016;22:965-70.

63 Bailly B, Dirr L, El-Deeb IM, et al. A dual drug regimen synergistically blocks human parainfluenza virus infection. Sci Rep 2016;6:24138.

64 Barik S, Lu P. Therapy of respiratory viral infections with intranasal siRNAs. Methods Mol Biol 2015;1218:251-62.

65 Falsey AR. Human Metapneumovirus Infection in Adults. Pediatr Infect Dis J 2008:27:S80-583.

66 Egli A, Bucher C, Dumoulin A, et al. Human metapneumovirus infection after allogeneic hematopoietic stem cell transplantation. Infection 2012;40:677-84.

67 El Chaer F, Shah DP, Kmeid J, et al. Burden of human metapneumovirus infections in patients with cancer: risk factors and outcomes. Cancer 2017:123:2329-37.

68 Larcher C, Geltner C, Fischer H, et al. Human metapneumovirus infection in lung transplant recipients: clinical presentation and epidemiology. The Journal of Heart and Lung Transplantation 2005;24:1891-901.

69 Dosanjh A. Respiratory metapneumoviral infection without co-infection in association with acute and chronic lung allograft dysfunction. J Inflamm Res 2015;8:79-82

70 Walter JM, Wunderink RG. Severe respiratory viral infections: new evidence and changing paradigms. Infect Dis Clin North Am 2017;31:455-74.

71 Wen X, Mousa JJ, Bates JT, et al. Structural basis for antibody crossneutralization of respiratory syncytial virus and human metapneumovirus. Nat Microbiol 2017;2:16272.

72 Bayon J-CL, Lina B, Rosa-Calatrava M, et al. Recent developments with live-attenuated recombinant paramyxovirus vaccines. Rev Med Virol 2013:23:15-34

73 Falloon J, Yu J, Esser MT, et al. An adjuvanted, postfusion F protein-based vaccine did not prevent respiratory syncytial virus illness in older adults. Infect Dis 2017.

74 Low SY, Tan TT, Lee CHK, et al. Severe adenovirus pneumonia requiring extracorporeal membrane oxygenation support - Serotype 7 revisited. Respir Med 2013;107:1810-3.

75 Louie JK, Kajon AE, Holodniy M, et al. Severe pneumonia due to adenovirus serotype 14: a new respiratory threat? Clinical Infectious Diseases 2008:46:421-5.

76 Lewis PF, Schmidt MA, Lu X, et al. A community-based outbreak of severe respiratory illness caused by human adenovirus serotype 14. J Infect Dis 2009;199:1427-34

77 Tan D, Zhu H, Fu Y, et al. Severe community-acquired pneumonia caused by human adenovirus in immunocompetent adults: a multicenter case series. PLoS One 2016:11:e0151199.

78 Kim SJ, Kim K, Park SB, et al. Outcomes of early administration of cidofovir in non-immunocompromised patients with severe adenovirus pneumonia. PLoS One 2015;10:e0122642.

79 Hiwarkar P, Amrolia P, Sivaprakasam P, et al. Brincidofovir is highly efficacious in controlling adenoviremia in pediatric recipients of hematopoietic cell transplant. Blood 2017;129:2033-7.

80 Hoke $\mathrm{CH}$, Snyder CE. History of the restoration of adenovirus type 4 and type 7 vaccine, live oral (Adenovirus Vaccine) in the context of the Department of Defense acquisition system. Vaccine 2013;31:1623-32.

81 Gern JE, Galagan DM, Jarjour NN, et al. Detection of rhinovirus RNA in lower airway cells during experimentally induced infection. Am J Respir Crit Care Med 1997:155:1159-61.

82 Falsey AR, Walsh EE, Hayden FG. Rhinovirus and coronavirus infection-associated hospitalizations among older adults. J Infect Dis 2002; 185:1338-41.
83 Seo S, Waghmare A, Scott EM, et al. Human rhinovirus detection in the lower respiratory tract of hematopoietic cell transplant recipients: association with mortality. Haematologica 2017;102:1120-30.

84 Sayah DM, Koff JL, Leard LE, et al. Rhinovirus and other respiratory viruses exert different effects on lung allograft function that are not mediated through acute rejection. Clin Transplant 2013;27:E64-71.

85 Kaiser L, Aubert J-D, Pache J-C, et al. Chronic rhinoviral infection in lung transplant recipients. Am J Respir Crit Care Med 2006;174:1392-9.

86 Ruuskanen $\mathrm{O}$, Waris M, Kainulainen L. Treatment of persistent rhinovirus infection with pegylated interferon $\alpha 2 \mathrm{a}$ and ribavirin in patients with hypogammaglobulinemia. Clinical Infectious Diseases 2014;58:1784-6.

87 Kkw T, Ccy Y, Yuen KY. Rhinovirus - From bench to bedside. J Formos Med Assoc 2017; 116:496-504.

88 Schnell D, Gits-Muselli M, Canet E, et al. Burden of respiratory viruses in patients with acute respiratory failure. J Med Virol 2014;86:1198-202.

89 World Health Organization. Emergencies preparedness, response: summary of probable SARS cases with onset of illness from 1 November 2002 to 31 July 2003. 2017. http://www.who.int/csr/sars/country/table2004_04_21/en/ (accessed 14 Oct 2017).

90 de Wit E, van Doremalen N, Falzarano D, et al. SARS and MERS: recent insights into emerging coronaviruses. Nat Rev Microbiol 2016:14:523-34.

91 WHO. Middle East Respiratory Syndrome Coronavirus (MERS-CoV). 2017 http://www.who.int/emergencies/mers-cov/en (accessed 28 Aug 2017).

92 Cheng Y, Wong R, Soo YOY, et al. Use of convalescent plasma therapy in SARS patients in Hong Kong. European Journal of Clinical Microbiology \& Infectious Diseases 2005:24:44-6.

93 Lee N, Allen Chan KC, Hui DS, et al. Effects of early corticosteroid treatment on plasma SARS-associated Coronavirus RNA concentrations in adult patients. Journal of Clinical Virology 2004;31:304-9.

94 Zumla A, Chan JFW, Azhar El, et al. Coronaviruses - drug discovery and therapeutic options. Nat Rev Drug Discov 2016;15:327-47.

95 Mo Y, Fisher D. A review of treatment modalities for middle east respiratory syndrome. J Antimicrob Chemother 2016;71:3340-50.

96 Falzarano D, de Wit $E$, Rasmussen $A L$, et al. Treatment with interferon- $\alpha 2 b$ and ribavirin improves outcome in MERS-CoV-infected rhesus macaques. Nat Med 2013;19:1313-7.

97 Mirouse A, Vignon P, Piron P, et al. Severe varicella-zoster virus pneumonia: a multicenter cohort study. Critical Care 2017:21:137.

98 Gregorakos L, Myrianthefs P, Markou N, et al. Severity of illness and outcome in adult patients with primary varicella pneumonia. Respiration 2002;69:330-4.

99 Lopez AS, Zhang J, Brown C, et al. Varicella-related hospitalizations in the United States, 2000-2006: the 1-dose varicella vaccination era. Pediatrics 2011:127:238-45

100 Styczynski J. Who Is the Patient at Risk of CMV Recurrence: a review of the current scientific evidence with a focus on hematopoietic cell transplantation. Infect Dis Ther 2017.

101 Boeckh M, Stevens-Ayers T, Travi G, et al. Cytomegalovirus (CMV) DNA Quantitation in bronchoalveolar lavage fluid from hematopoietic stem cell transplant recipients with CMV Pneumonia. J Infect Dis 2017:215:1514-22.

102 Saugel B, Jakobus J, Huber W, et al. Herpes simplex virus in bronchoalveolar lavage fluid of medical intensive care unit patients: Association with lung injury and outcome. J Crit Care 2016;32:138-44

103 Frobert E, Billaud G, Casalegno J-S, et al. The clinical interest of HSV1 semi-quantification in bronchoalveolar lavage. Journal of Clinical Virology 2013;58:265-8.

104 Bonizzoli M, Arvia R, di Valvasone S, et al. Human herpesviruses respiratory infections in patients with acute respiratory distress (ARDS). Med Microbiol Immunol 2016:205:371-9.

105 Steiner M, Strassl R, Straub J, et al. Nosocomial rhinovirus infection in preterm infants. Pediatr Infect Dis J 2012:31:1302-4.

106 Hoellein A, Hecker J, Hoffmann D, et al. Serious outbreak of human metapneumovirus in patients with hematologic malignancies. Leuk Lymphoma 2016;57:623-7.

107 Tablan OC, Anderson LJ, Besser R, et al. Guidelines for preventing health-care-associated pneumonia, 2003: recommendations of CDC and the Healthcare Infection Control Practices Advisory Committee. MMWR Recomm Rep 2004;53:1-36

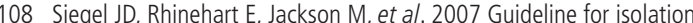
precautions: preventing transmission of infectious agents in health care settings. Am J Infect Control 2007:35:S65-164.

109 Lehners N, Tabatabai J, Prifert C, et al. Long-Term shedding of influenza virus, parainfluenza virus, respiratory syncytial virus and nosocomial epidemiology in patients with hematological disorders. PLoS One 2016;11:e0148258. 